\title{
Application of digital image correlation system for reliable deformation capturing of concrete structures at elevated temperatures
}

\author{
Dinh Ba Le ${ }^{1}$, Son Duy Tran ${ }^{1}$, Jose L. Torero ${ }^{1,2}$, Vinh T. N. Dao ${ }^{1, *}$ \\ Engineering Structures \\ ${ }^{1}$ School of Civil Engineering, University of Queensland, Brisbane, Australia. \\ ${ }^{2}$ School of Engineering, The University of Maryland, USA. \\ *Corresponding author: Email:v.dao@uq.edu.au
}

\section{Abstract}

Reliable deformation measurement is required for proper quantification of fire performance of concrete structures. Predictive capability of models for many critical properties, including Young's moduli, stress-strain relationships and load-induced thermal strains, is first and foremost dependent on such reliable deformation capturing.

This paper first presents a state-of-the-art review of existing methods for capturing deformation of concrete structures at elevated temperatures. Key merits, limitations and challenges associated with each measuring technique are discussed. It is shown that existing testing facilities and measuring instruments generally do not allow reliable direct measurement of displacement and strain of high-temperature concrete. As a result, the deformation has typically been captured either indirectly or outside the heated zones, inevitably introducing additional uncertainties and errors that are difficult to be adequately quantified.

On the basis of that review, the paper details a new test setup for reliable, non-contact fullfield deformation capturing of concrete structures at high temperatures using 3D Digital Image Correlation technique. Key features of the new setup that enable to successfully address major challenges of thermal boundary condition, thermal stability of speckle pattern, contrast of image and hot air movement are highlighted. Evidence giving confidence to the reliability of the new setup are then presented, together with likely applications of such setup and their potential positive impact on the ongoing transitioning towards performance-based structural fire engineering.

Keywords

Concrete; elevated temperatures; fire; deformation capturing; DIC. 


\section{Introduction}

The outbreak of a fire in buildings and civil engineering structures can have potentially disastrous consequences, including severe structural damage, significant loss of contents and possible loss of life. In the event of a large fire, the difficulties associated to structural integrity assessment can even hamper fire fighters' response. Adequate design for fire is thus an essential requirement in the design process, highlighting the critical need for adequate understanding of the performance of structural systems in fire. Such an understanding requires, among other things, reliable realistic measurements of thermal and deformational response of structures at elevated temperatures.

Unfortunately, most existing experimental data have been collected in conventional furnaces or in compartment fire conditions where the characterization of thermal exposure conditions carries significant uncertainty $[1,2]$ and reliable deformation measurement are difficult to perform $[3,4]$. The implications of these limitations and challenges on the reliability of collected experimental data, and by extension the analytical and numerical models developed on the basis of such data, are typically more severe for the case of concrete and concrete structures $[1,3,4]$. A research program is thus ongoing at the University of Queensland with a focus to generate a more reliable and realistic set of data for (i) improved understanding of concrete behaviour in fire conditions and (ii) improved analytical and numerical models for performance-based structural fire design of concrete structures.

This paper first presents a brief review of existing methods for capturing deformation of concrete structures at elevated temperatures, highlighting their key limitations and remaining challenges. On that basis, the paper reports details of a new test setup for reliable, non-contact full-field deformation capturing of concrete surfaces at elevated temperatures using 3D Digital Image Correlation technique. Evidence giving confidence to the reliability of the new setup is also presented, together with likely applications of such setup and their potential positive impact on the ongoing transitioning towards performance-based structural fire engineering of concrete structures.

\section{Review on methods for capturing deformation of concrete specimens at elevated temperatures}

Methods for measuring deformation can be classified into: (i) contact and non-contact groups in terms of the technologies involved; (ii) displacement and strain categories with regard to the type of data collected; and (iii) local or full-field class for measuring capacities. This section first summarises a variety of methods and instruments involved in deformation measurement of concrete at high temperatures, followed by a discussion of the key challenges and the applicability of these methods at elevated temperatures. Based on this thorough review, digital image correlation is identified as among the most feasible techniques for its capability and reliability. 


\subsection{Contact methods}

- Linear position transducer (LPT) and linear variable differential transformer (LVDT)

LPT and LVDT are amongst the most commonly used instruments to measure deformation in fire tests of concrete at both material and structural levels due to their simple installation as well as their providing highly accurate measurements outside the heated zones. LPT measures the amount of wire drawn from a spool during deformation measuring while LVDT (Figure 2.1a,b) measures translational displacements through induced voltage changes as the core moves through electromagnetic coils.

In previous experimental studies on mechanical properties of concrete at elevated temperatures $[5,6]$, LVDTs were utilized to measure the overall displacement of concrete specimens. The collected data under different combinations of loading and heating levels were then used to study the variation of elastic modulus and different components of strain (including free thermal, load-induced thermal and residual strains).

These instruments were also employed in many fire tests of concrete structural elements to measure the axial and lateral displacements of the test specimens. Axial displacements were normally taken directly by LPTs or LVDTs at the edges of the objects and outside the heated zones [7-13]. Given that the tests were conducted in furnaces, lateral deformation had to be estimated with devices with low thermal expansion such as ceramic rods and invar bars. These devices had to be used as an intermediate system to transfer the displacements out of the heated regions to the transducers $[11,14]$.

Using LVDTs at the end of a measurement system, Sullivan, Khoury [6] reported that reliable measurements could be achieved: The errors of measured thermal expansion of copper specimens were reported as less than 100 microstrains and the coefficient of thermal expansion was reported within the range of $\pm 2 \%$ of the known value - However, there appeared uncertainties associated with the use of many intermediate devices/connections that had not been properly quantified.

\section{- Compressometer}

A compressometer is capable of capturing deformation of concrete cylinders up to the peak load level [15-17]. Figure 2.1c shows a compressometer with two rings and three displacement transducers connected to concrete cylinders via thin rods [15]. Another setup of compressometer is presented in Figure 2.1d [16], including two Inconel rods that contacted the specimen surfaces through cut-out slots on the furnace walls.

Furnace-mounted compressometers were reportedly very sensitive to any disturbances such as closing the furnace door, testing machine vibration and prolonged exposure to high temperatures [18]. In another study (Figure 2.1e) [17], the device was used to capture the deformation of specimens up to only $40 \%$ of their compressive capacity at corresponding target temperature. It had to be removed by then to avoid damage to aluminium rods due to the sudden crushing of specimens. 


\section{- High temperature strain gauge}

There has been very limited success in using strain gages in fire testing of concrete structures. Strain gauges can be bonded to the concrete surface or the reinforcement, or embedded in the concrete section $[13,19,20]$. The performance of high temperature strain gauges thus depends not only on their inherent performance at elevated temperatures but also on the bonding as well as the differential thermal deformation between them and the concrete/steel substrate. Accordingly, their performance at elevated temperatures remain rather variable and unreliable [3], prompting further research to develop improved strain gauges for concrete structures in fire conditions.

\section{- Fiber-optic sensor}

These sensors are fiber-based devices that use optical fibers to capture the strain along their entire length. They have been utilized to measure the strain of fibre reinforced polymer (FRP) and longitudinal reinforcement in fire tests of FRP strengthened RC beams [21]. Common sensors coated with acrylate can only work up to $80^{\circ} \mathrm{C}$ while carbon/polyimide coating is claimed to enhance the sensors' workability range up to $450^{\circ} \mathrm{C}$.

\section{- Challenges of using contact methods at elevated temperatures}

Contact methods including LPTs, LVDTs and strain gauges are inapplicable because their wire leads are not able to sustain the heat and soon damaged at early stages of the tests [22]. The use of LPTs and LVDTs in fire conditions requires thermal protection or suitable materials for exposure to elevated temperatures (such as those with low thermal expansion, high melting points and no phase transformation up to the target temperature of interest). In most instances, the displacements of test specimens have to be transferred out of the heated zone by intermediate devices, thereby introducing additional uncertainties and errors that are difficult to be appropriately quantified [5]. With regard to strain gages, improved understanding of their thermal response and interaction with concrete/reinforcement substrate at elevated temperatures is required [3].

Fiber-optic sensors are also inappropriate in fire conditions due to their relatively low working temperatures [21]. Although special adhesives such as ceramic may extend the sensors' workable range up to $450^{\circ} \mathrm{C}$ or even higher [23], further work is required to establish the reliability of not only the fiber-optic sensors but also the good contact between the sensors and surrounding concrete [3].

\subsection{Non-contact methods}

\section{- Laser sensor}

Laser sensors project a laser light spot on the measuring subject and then receive the reflection on a high-sensitivity resolution element [24]. This device provides a spatial, non- 
destructive solution for measuring point-wise displacement. Current versions of laser sensors perform poorly in fire conditions due to fire spectrum interference at the laser frequency while being often costly [3]. Due to the above and also to the high risk of damage, the use of laser sensors in fire testing has been rather limited.

\section{- Digital image correlation (DIC)}

DIC is a photogrammetric technique, which uses cameras to capture images of an object, storing them in digital form and then analysing to extract full-field shape and deformation [25]. DIC systems process sequential images to compute surface measurements of displacement and strain. Theory and application of the technique at ambient temperature have been well established. The method was used in many experimental studies to examine the deformation of concrete at room temperature, including the structural response of heat-damaged RC columns confined with carbon fibre reinforced polymer fabrics [26], fatigue behaviour of strengthened RC beams [27], shear capacity of prestressed concrete structures [28, 29] and crack propagation in lightly RC beams [30]. These studies have confirmed the accuracy and reliability of DIC measurements for concrete deformation at ambient temperature. However, there has not been any similar research undertaken on concrete specimens at elevated temperatures.

\section{- Challenges of using non-contact methods at elevated temperatures}

The hot gases, sooting particles and thermal induced radiation in furnaces are the common obstacles for non-contact, optical methods. They interact with the light travelling from the objects to the measuring instruments, disturb the collected data and lead to errors in obtained measurements. Laser sensors have failed to work in fire environment because the thermal radiation interferes with the laser frequency [3].

Regarding fire tests implemented in a closed configuration such as conventional furnaces [31, 32], DIC measurements had to be taken from outside of the heating facilities and throughout their windows. The quality of these windows, heat haze caused by hot air circulation, thermal stability of speckle patterns on surfaces of the test specimens and the consistency of lighting conditions are the additional critical issues that influence the reliability of DIC performance. 
(a)

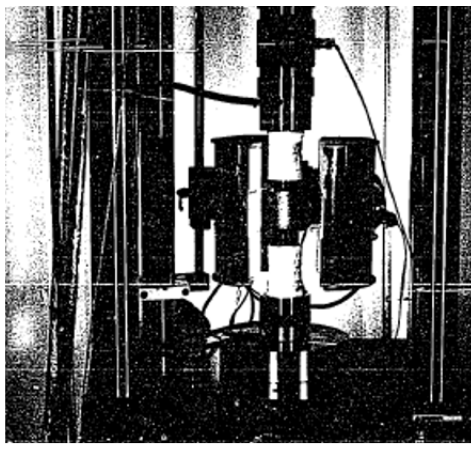

(b)
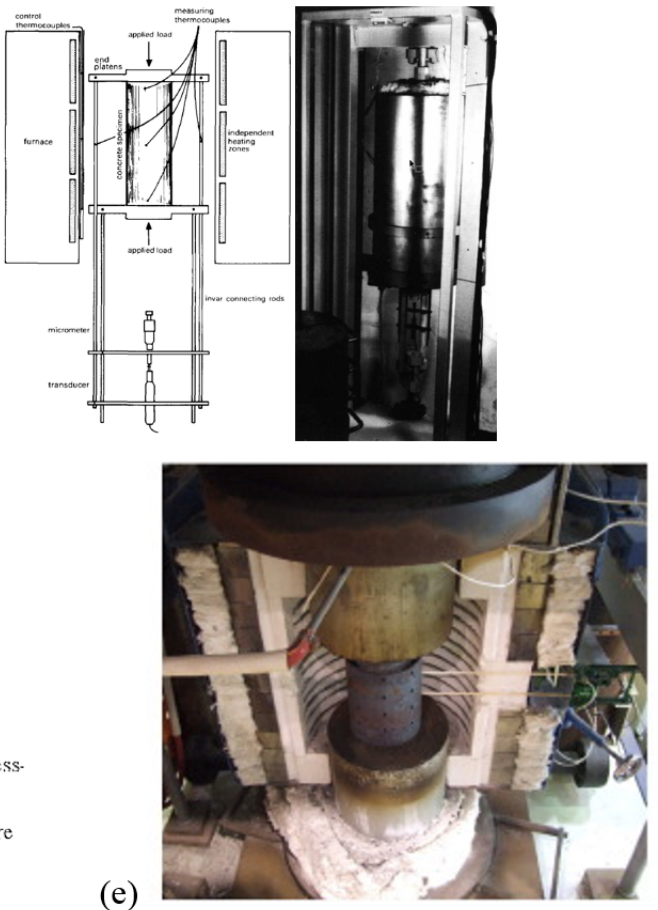

(c)

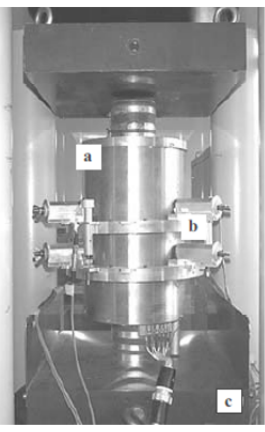

(d)

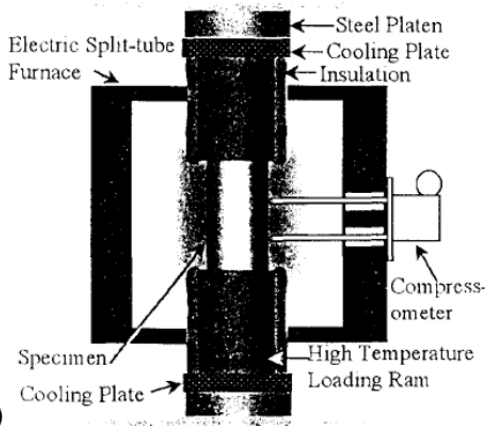

(e)

(c) (d) (e) $[15,16,33]$.

\subsection{Discussion}

It can be inferred from the above review that measurement of structural displacements and strains has been mostly performed outside the heated zone in previous fire tests of concrete. The extremely hot environments in conventional furnaces that are commonly used in the experiments limit the workability of almost all contact methods. With regard to non-contact, optical methods, hot air circulation, sooting particles and thermal induced radiation in furnaces are the major challenges affecting their applicability. The issues associated with each method are summarised in Table 1.

Table 1. Challenges in deformation capturing of concrete at elevated temperature.

\begin{tabular}{|c|c|c|c|}
\hline \multirow{4}{*}{ 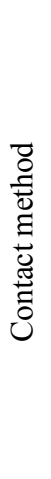 } & Instruments & $\begin{array}{l}\text { Measurement } \\
\text { capacity }\end{array}$ & Challenges in conditions of elevated temperatures \\
\hline & $\begin{array}{c}\text { LPT, LVDT } \\
\text { Compressometer }\end{array}$ & $\begin{array}{l}\text { Point-wise } \\
\text { displacement }\end{array}$ & $\begin{array}{l}\text { Thermal protection or thermally stable sensor is required when exposed to } \\
\text { elevated temperatures. }\end{array}$ \\
\hline & $\begin{array}{l}\text { High } \\
\text { temperature } \\
\text { strain gauge }\end{array}$ & Loce & $\begin{array}{l}\text { The workable temperature range for normal strain gauges is typically up to } \\
\text { about } 100^{\circ} \mathrm{C} \text { in concrete structures. High-temperature strain gages require } \\
\text { further development for improved reliability and range of applicability. }\end{array}$ \\
\hline & $\begin{array}{l}\text { Fiber-optic } \\
\text { sensor }\end{array}$ & $\begin{array}{l}\text { Multipoint or } \\
\text { continuous strain } \\
\text { along a fiber }\end{array}$ & $\begin{array}{l}\text { Sensor integrity and bonding methods are not reliable at elevated } \\
\text { temperatures and need to be improved. Strains transferred from the specimen } \\
\text { to the sensor need to be classified and isolated. }\end{array}$ \\
\hline \multirow{2}{*}{ 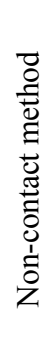 } & Laser sensor & $\begin{array}{l}\text { Point-wise } \\
\text { displacement }\end{array}$ & $\begin{array}{l}\text { Laser beam is interfered and distorted by radiated and reflected light from } \\
\text { fires. Further developments in laser frequencies and signal processing } \\
\text { techniques are needed for successful application in fire conditions. }\end{array}$ \\
\hline & $\begin{array}{l}\text { Digital Image } \\
\text { Correlation }\end{array}$ & $\begin{array}{c}\text { Full-field } \\
\text { displacement }\end{array}$ & $\begin{array}{l}\text { Methods to minimise the adverse effects from thermal radiation, smoky and } \\
\text { air turbulent conditions are required. } \\
\text { Thermal stability of speckle has to be ensured. } \\
\text { Quantification of errors and uncertainties needs to be developed. }\end{array}$ \\
\hline
\end{tabular}


Amongst these instruments, DIC is recognised as among the most potential candidates for deformation capturing at elevated temperatures. Indeed, this method was successfully applied in experiments involving metallic specimens [34-37]. The key difference between testing concrete and metallic materials at elevated temperatures lies in the heating method. Conventional furnaces were commonly adopted in fire tests of concrete, in which strong heat haze, smoke and soot particles are unavoidable. In contrast, temperatures of metallic specimens can be effectively elevated by infrared or ohmic heaters, which are non-smoky heating facilities.

The successful practices of DIC for deformation capturing on heated metallic specimens and the development of a non-smoky, reliable heating system for concrete using radiant panels [2] encourage the authors to develop an analogous test setup to use in fire tests of concrete. The key features and detailed application are presented in the following sections.

\section{A new test setup using DIC technique for deformation capturing of concrete specimens at elevated temperatures}

As reliable realistic data on both thermal and deformational behaviour of concrete specimens at elevated temperatures are required to fully understand the performance of concrete structures in fire and also to validate analytical/numerical models of their performance in fire conditions, a new test setup has been developed at the University of Queensland to enable the generation of such data [38]. The thermal boundary condition is delivered by means of radiant panels in a manner consistent with the objectives described by Maluk, Bisby [39]. In addition to the capability of imposing reliable thermal boundary conditions on test specimens, the setup also provides a heating solution without smoke, flame or soot particles, facilitating the application of such optical measuring techniques as DIC.

In this section, key features of a new setup for full-field non-contact deformation capturing of concrete surface at elevated temperatures are first given, followed by a presentation of evidences that give confidence to the reliability of such system.

\subsection{Test apparatus and instrumentation}

This experimental program employs a system of four radiant panels symmetrically positioned around concrete cylinders of $100 \mathrm{~mm}$ in diameter and $200 \mathrm{~mm}$ in height for thermal loading. This heating facility is capable of generating an essentially uniform heat flux level around the test specimens and thereby effectively overcoming the limitation of inconsistent thermal boundary conditions in conventional fire tests [38, 39].

Loading is imposed by an actuator attached to a steel frame. The loading machine is protected against heat, which allows the application of radiant panels while maintaining the initial applied load. The test apparatus, therefore, is capable of investigating the fire performance of concrete structures under different load-temperature paths. 
Regarding the measuring technique, digital image correlation technique is adopted to undertake direct and full-field deformation of concrete exposed to the radiant panels. Figure 3.1 illustrates the arrangement of testing specimens and instrumentation.

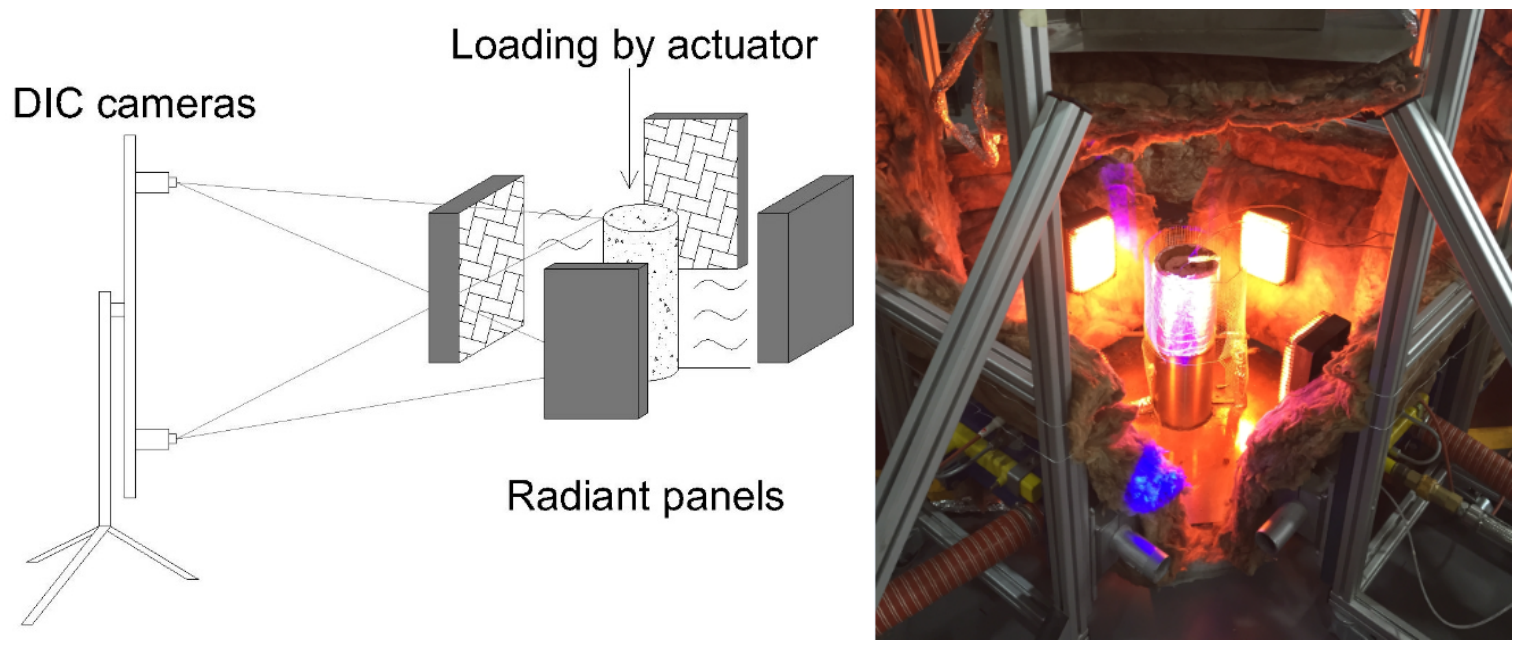

Figure 3.1. Test setup and instrumentation for deformation capturing.

\subsection{Key features of the new setup for deformation capturing using stereo DIC technique}

In DIC technique, displacement field on the visible surfaces of test specimens is obtained by comparing and tracking the locations of subsets of pixels in digital images captured continuously during testing at specified time intervals. The accuracy of DIC technique, thus, relies significantly on the quality of the images, which is in turn influenced by the quality of the applied speckle pattern, the stability of lighting condition and the accuracy of the calibration process. The area of interest must have a high contrast random pattern to ensure that the analysis software can recognise the positions of corresponding subsets on the deformed surface, while the light intensity needs to be stable to maintain a relatively consistent level of overall contrast. The challenges associated with these factors are identified and summarised in Section $\S 2$ and Table 1. The following briefs key features of the test setup that help address these challenges.

\section{- Speckle patterns}

The speckle pattern is computationally designed in accordance with practical considerations for accurate measurements with DIC technique [25]. The speckle size is about 5-10 pixels on captured images and the speckles cover approximately $50 \%$ of total pattern area. Silicon ceramic paint VHT Flame Proof, which is workable up to $1000^{\circ} \mathrm{C}$ as specified by the manufacturer, is used to ensure the stability of the pattern within the temperature range of interest. The designed pattern is fabricated on a piece of paper using a laser cutting machine.

The cylinder surfaces are first coated with a thin layer of VHT Flameproof ${ }^{\mathrm{TM}}$ SP102 flat white to form the background, followed by an application of VHT Flameproof ${ }^{\mathrm{TM}}$ SP101 flat black speckles. The black speckles are applied by spraying black high-temperature paints over the pre-fabricated laser-cut paper attached on the surface of the cylinders. This method ensures that the customised pattern is appropriately applied on the surfaces of test specimens. In 
addition, the use of only thermal paints warrants the stability of the pattern at elevated temperatures.

- Band-pass filter, blue illumination and optical properties of imaging system

At elevated temperatures, the increasing intensity of the light emitted and reflected from specimens' surface and from radiant panels negatively affects the quality of images. As evidenced in Figure 3.2b, the image becomes saturated if measures are not taken to minimise the effects of such increasing light intensity during heating. Therefore, a Midopt BP470 filter is employed to minimise the effect of thermal radiation, together with an EFFI-Lase-PowerCM-C02-465 blue light to enhance the lighting condition. Such use of band-pass filter and blue illumination has proved to be very effective, as shown in Figure 3.2c. The spectral properties of these lighting components as well as the Sony ICX625 CCD sensor of DIC cameras are plotted in Figure 3.3. These properties are essential for theoretical assessment on the effectiveness of the whole system against the effect of thermal radiation, which is demonstrated in the next section.

a)

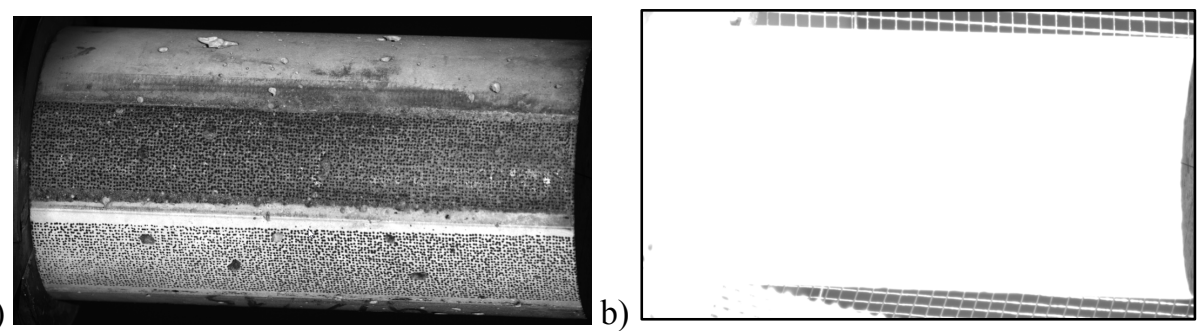

c)

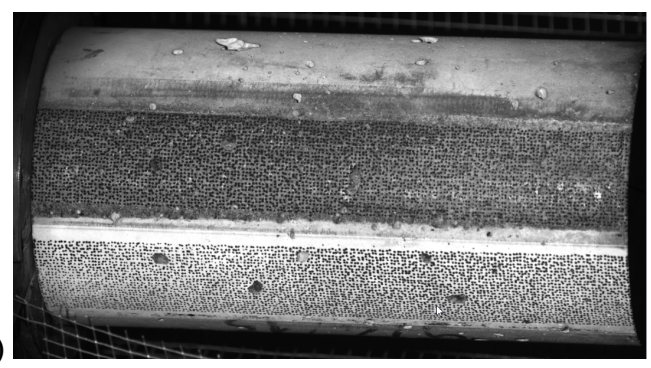

Figure 3.2. Captured images: at ambient temperature (a); at elevated temperatures without and with blue light and band-pass filter ((b) and (c) respectively). 


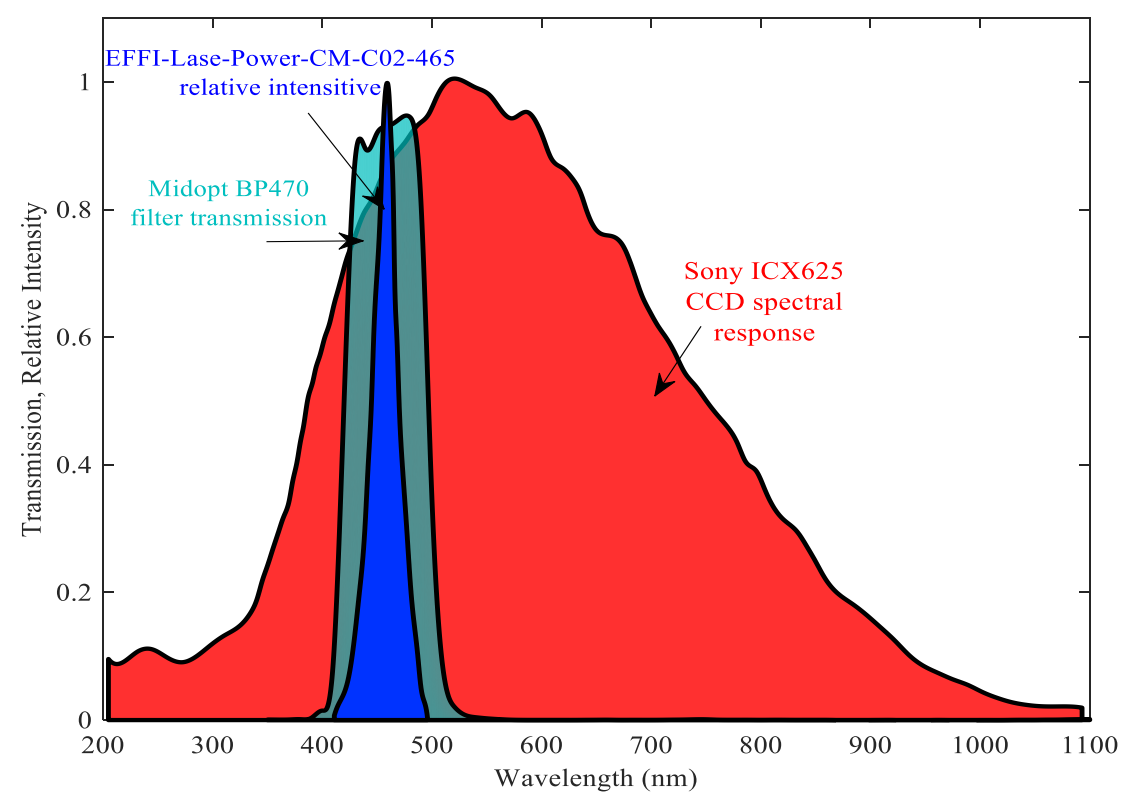

Figure 3.3. Spectral properties of the camera sensor, band-pass filter and blue light.

\subsection{Assessment on the effectiveness of the imaging system against the effect of thermal} radiation at elevated temperatures

Although the DIC technique was successfully employed in many experimental studies on metallic specimens heated up to $2600^{\circ} \mathrm{C}$ [34-36], thermal radiation remained the key challenge associated with the application of this technique beyond $600^{\circ} \mathrm{C}$ in these studies.

Planck's radiation law specifies the spectral emissive power $I_{\lambda}(\lambda, T)$ released in normal direction from a black body specimen at an absolute temperature $T$ and particular wavelength $\lambda$ as follows:

where

$$
I(\lambda, T)=\frac{2 \pi h c_{0}^{2}}{\lambda^{5}\left(e^{h c_{0} / \lambda k T}-1\right)}
$$

$$
\begin{array}{ll}
h & \text { Planck's constant, } \\
k & \text { Boltzmann's constant, and } \\
c_{o} & \text { speed of light in vacuum. }
\end{array}
$$

The accumulative radiated energy at an absolute temperature $\mathrm{T}$ within a range of wavelength $\left(\lambda_{1}, \lambda_{2}\right)$ is:

$$
E_{\lambda_{1}, \lambda_{2}}(T)=\int_{\lambda_{1}}^{\lambda_{2}} I(\lambda, T) \partial \lambda=2 \pi h c_{0}^{2} \int_{\lambda_{1}}^{\lambda_{2}} \frac{\partial \lambda}{\lambda^{5}\left(e^{h c_{0} / \lambda k T}-1\right)}
$$

Based on these formulae, the thermal radiation from a specimen at elevated temperature can be determined and plotted in Figure 3.4 and Figure 3.5. It can be seen from the Figure 3.4 that the amount of radiated energy increases substantially with the temperature of the specimen. In addition, the peak of the energy distribution gradually shifts to the visible range and captured by the DIC cameras. This interference alters the lighting condition and subsequently the contrast of obtained images, causing decorrelation and errors in DIC results as evidenced in Figure 3.2b. 
Figure 3.5 also shows that the amount of total energy within the visible wavelength increases significantly with temperature. Previous experimental studies indicate that decorrelation initiates at about $600^{\circ} \mathrm{C}$, at which the total energy from thermal radiation is approximately $0.9 \mathrm{~W} / \mathrm{m}^{2}$. The figure also indicates that this radiated energy can be significantly reduced by employing a blue band-pass filter and limiting the transferable wavelength within the range from $410 \mathrm{~nm}$ to $510 \mathrm{~nm}$. With the application of a blue filter, the same level of thermal radiation energy $\left(0.9 \mathrm{~W} / \mathrm{m}^{2}\right)$ can only be achieved at about $1200^{\circ} \mathrm{C}$. The drawback of this application is that it also reduces the light intensity from other sources of illumination. The contrast of captured pictures is consequently compromised due to low level of brightness.

These properties of thermal radiation are the key for Grant, Stone [35] to develop a countermeasure using a combination of band-pass filter and blue illumination with the aim to minimise the amount of thermal radiation transmitted to the camera sensors. A similar approach was employed in several studies using DIC technique at elevated temperatures [34, 36, 37].

In the current test setup, the illumination sources can be either stabilising or disturbing The aim is to ensure that the stabilising source of illumination remains dominant during testing:

- The controllable and stabilising source of illumination comes from the EFFI-LasePower-CM-C02-465. The LED light provides a reliable and uniform illumination with peak wavelength of $465 \mathrm{~nm}$, which can be effectively transmitted throughout the Midopt BP470 filter.

- The disturbing illumination arises from thermal radiation of radiant panels and heated specimens. While the test specimens at elevated temperatures radiate energy direct to camera sensors, thermal emission from heating panels travels to the surfaces of test specimens, reflects and is captured by DIC cameras.

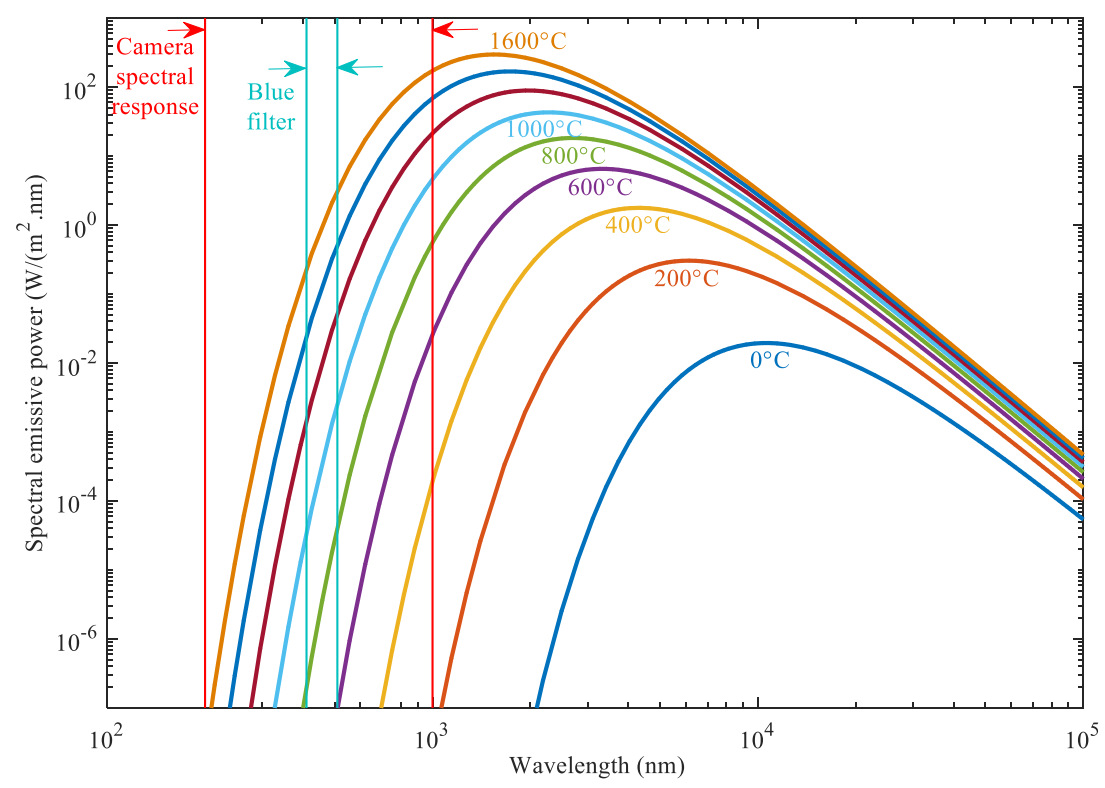

Figure 3.4. Spectral emissivity power for different temperatures. 


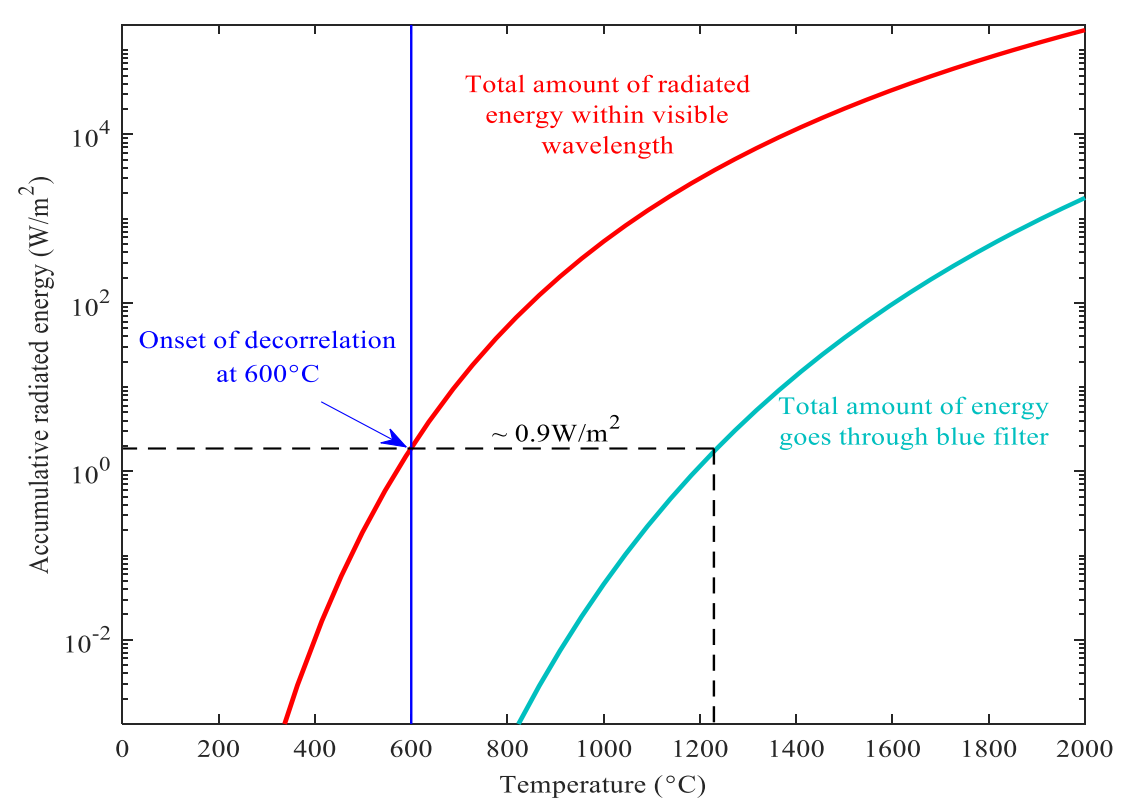

Figure 3.5. Accumulative thermal radiated energy as temperature increases.

A theoretical examination in the light intensity is presented to demonstrate that the lighting condition is stable throughout the experiments without significant interference caused by thermal radiation, by comparing energy captured by DIC cameras from different sources of illumination. The investigation is undertaken by calculating the light intensity leaving the surfaces of test specimens, going through the filter and being captured by the DIC camera sensors, with following assumptions:

a. White speckles are perfect reflecting surfaces (with emissivity being approximately 0 ) and black speckles are perfect emitting surfaces (with emissivity being approximately 1). This assumption is reasonable as the VHT Flameproof ${ }^{\mathrm{TM}} \mathrm{SP} 102$ flat white used for background coating contains titanium dioxide, which is capable of reflecting almost all visible wavelengths [40]; while the VHT Flameproof ${ }^{\mathrm{TM}}$ SP101 flat black paint has been proved to be a high emissivity coating [41]. Based on this assumption, the accumulative area of reflectors is equal to that of emitters because the density of the black speckles is approximately 50 percent of total area.

b. The temperature and heat flux at surfaces of the radiant panels are $1400^{\circ} \mathrm{C}$ and $200 \mathrm{~kW} / \mathrm{m}^{2}$ respectively. The incident heat flux at surfaces of the specimens is $20 \mathrm{~kW} / \mathrm{m}^{2}$. These assumptions were calculated based on the specifications given by the manufacturer and actual calibration before testing.

c. Reflected thermal radiation of radiant panels at cylinder surfaces has the same spectral emissive power per wavelength as at surfaces of radiant panels.

Based on these assumptions, thermal radiation emitted by a test specimen at certain temperature T, passing through the filter and captured by DIC camera sensors can be calculated as follows:

$$
E_{S}(T)=2 \pi h c_{0}^{2} \int_{410}^{510} \frac{f_{B}(\lambda) f_{C}(\lambda)}{\lambda^{5}\left(e^{h c_{0} / \lambda k T}-1\right)} \partial \lambda
$$


where $\quad f_{B}(\lambda)$ is the transmission function of the band-pass filter;

$f_{C}(\lambda)$ is the spectral response of DIC camera sensor.

Similarly, the radiated energy leaving the radiant panels, reflecting at the surface of the specimen, transmitting through the band-pass filter and finally being captured by the camera sensor can be estimated by:

$$
E_{R}=\left(2 \pi h c_{0}^{2} \int_{410}^{510} \frac{f_{B}(\lambda) f_{C}(\lambda)}{\lambda^{5}\left(e^{h c_{0} /(\lambda k \times 1673}-1\right)} \partial \lambda\right) \times \frac{1}{10}=1.14\left(\mathrm{~W} / \mathrm{m}^{2}\right)
$$

The ratio 1/10 accounts for the reduction in thermal radiation energy from the surface of radiant panels $\left(200 \mathrm{~kW} / \mathrm{m}^{2}\right)$ to the surface of the specimens during testing $\left(20 \mathrm{~kW} / \mathrm{m}^{2}\right)$.

The power consumption of the EFFI-Lase-Power-CM-C02-465 blue LED illumination is $15 \mathrm{~W}$ [42]. As there is no information given for radiometric power, the energy efficiency of this LED light is conservatively assumed as low as 10 percent. The optical power of this source of illumination is consequently $1.5 \mathrm{~W}$. With the working distance of $0.8 \mathrm{~m}$ away from the sample surfaces, the LED lights a circular area of $0.3 \mathrm{~m}$ diameter. The amount of energy reflected at the surfaces of the specimens and captured by the camera sensor can be estimated by the following function:

$$
E_{L E D}=\frac{1.5}{\pi \times 0.15^{2}} \times \frac{\int_{410}^{510} f_{B}(\lambda) f_{C}(\lambda) f_{L E D}(\lambda) \partial \lambda}{\int_{410}^{510} f_{L E D}(\lambda) \partial \lambda}=16.6\left(\mathrm{~W} / \mathrm{m}^{2}\right)
$$

The ratio of the disturbing to the stabilizing illuminations is subsequently determined as follows:

$$
R(T)=\frac{E_{L E D}}{E_{R}+E_{S}(T)+E_{L E D}}
$$

This ratio is plotted as a function of temperature in Figure 3.6. It can be inferred from this plot that the LED light is the dominant source of illumination in the imaging system, which accounts for at least 90 percent of the energy captured by the DIC cameras. The effect of thermal radiation can be effectively minimised at up to $1200^{\circ} \mathrm{C}$ even if the efficiency of the LED light is assumed at 10 percent. The images captured by the system in Figure 3.7 (and Figure 3.2) experimentally confirm that the effect of thermal radiation on the lighting condition is negligible. Indeed, the analysis demonstrates that this DIC setup is capable of working at even higher temperatures by increasing the power of the blue light to overcome the thermal radiation. 


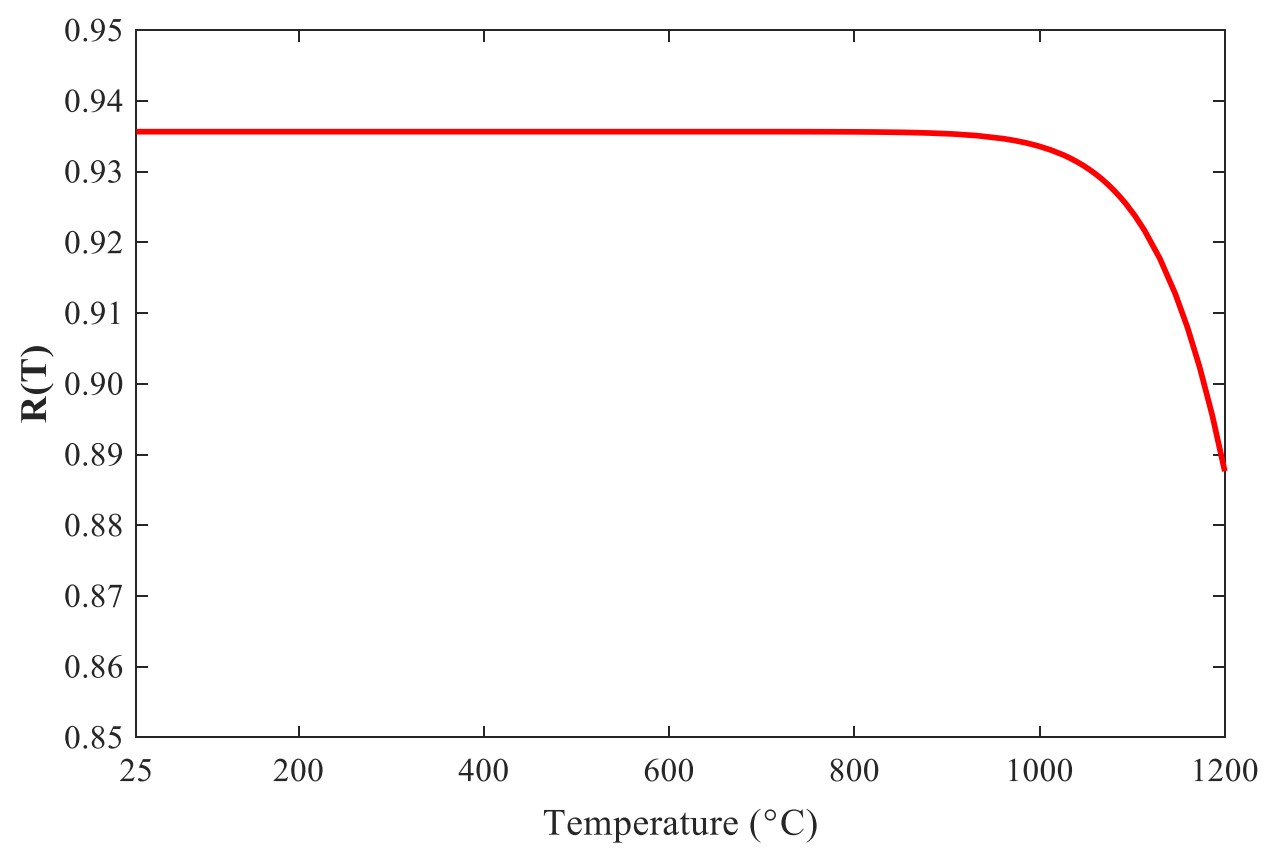

Figure 3.6. Variation of the ratio between the destabilising to the stabilizing illuminations with temperatures and efficiency of the blue LED light.

(a)
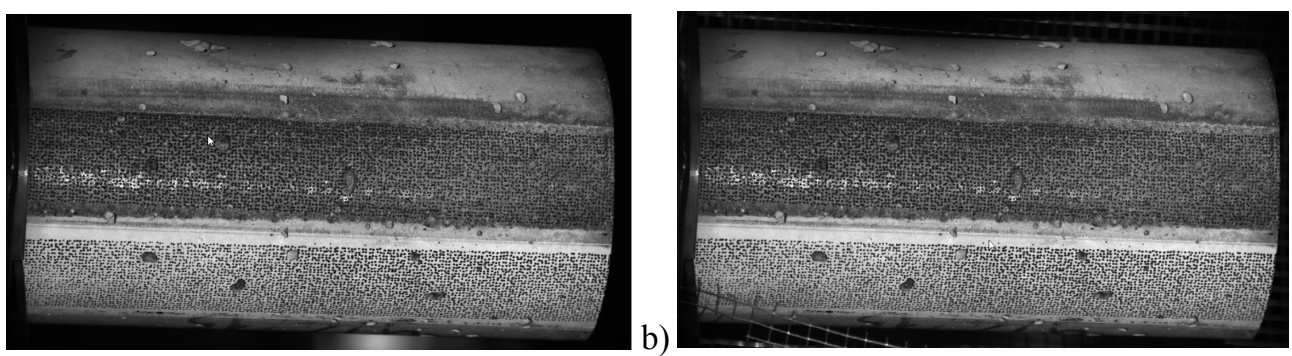

c)

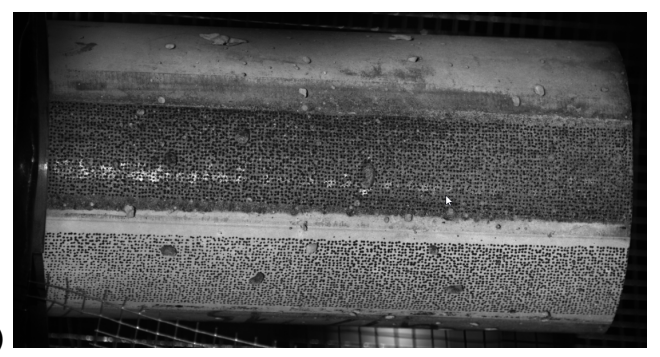

Figure 3.7. Captured images with the LED blue light and filter at ambient temperature (a), when radiant panels were on (b) and when the panels were off (c).

\section{Test results and discussion}

In this section, the reliability of the newly-developed DIC system for deformation capturing both at ambient and elevated temperatures will be demonstrated. First, the deformation captured by the new DIC system, the actuator and strain gauges at ambient temperatures will be compared to establish the relevant reliability of each method (Section 4.1). The reliability of the new DIC system at elevated temperatures will then be established through comparing with deformation recorded by the actuator (Section 4.2) and also through rigid motion test (Section $4.3)$. 
This step aims to experimentally assess the reliability of deformation captured by the DIC technique at ambient temperature by comparing its results with data collected from an actuator and strain gauges. The test setup is as shown in Figure 4.1. Test specimens were concrete cylinders of $\phi 100 \mathrm{~mm}$ in diameter and $200 \mathrm{~mm}$ in height. Three $60 \mathrm{~mm}$ strain gauges were attached on the surface of each specimen as illustrated in Figure 4.2. The DIC system included two 5-megapixel cameras and $75 \mathrm{~mm}$ lenses. The captured images were analysed by VIC 3D 2010 software [43] to extract required displacements and strains. Results are plotted in Figure 4.3 .
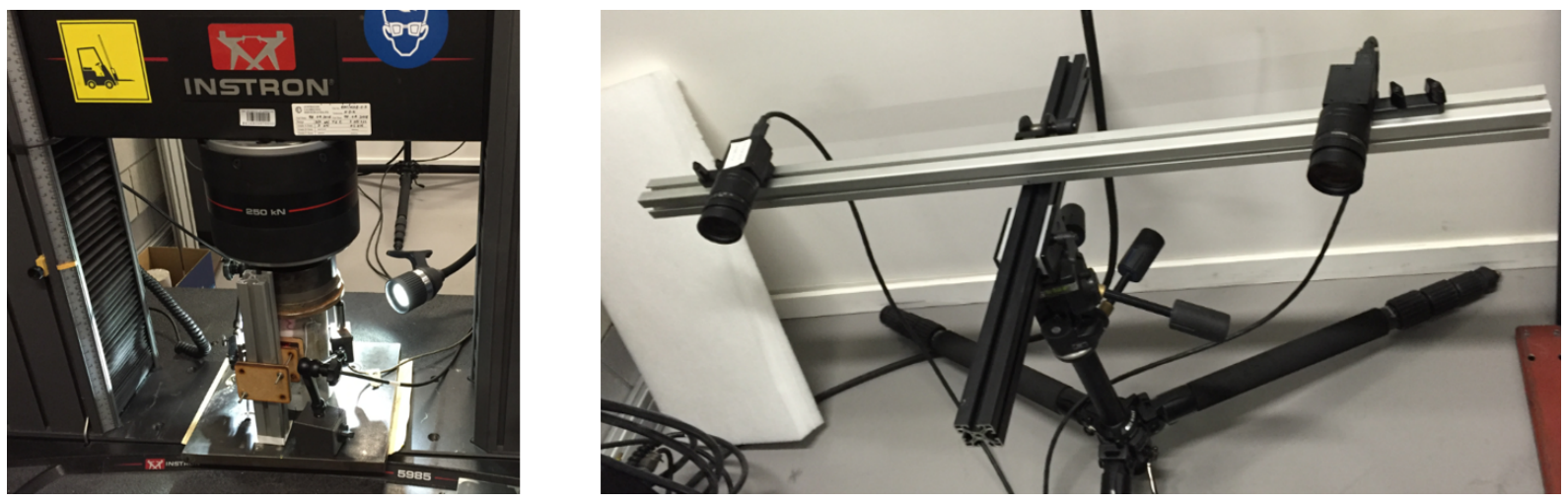

Figure 4.1. The DIC setup and the Instron machine.
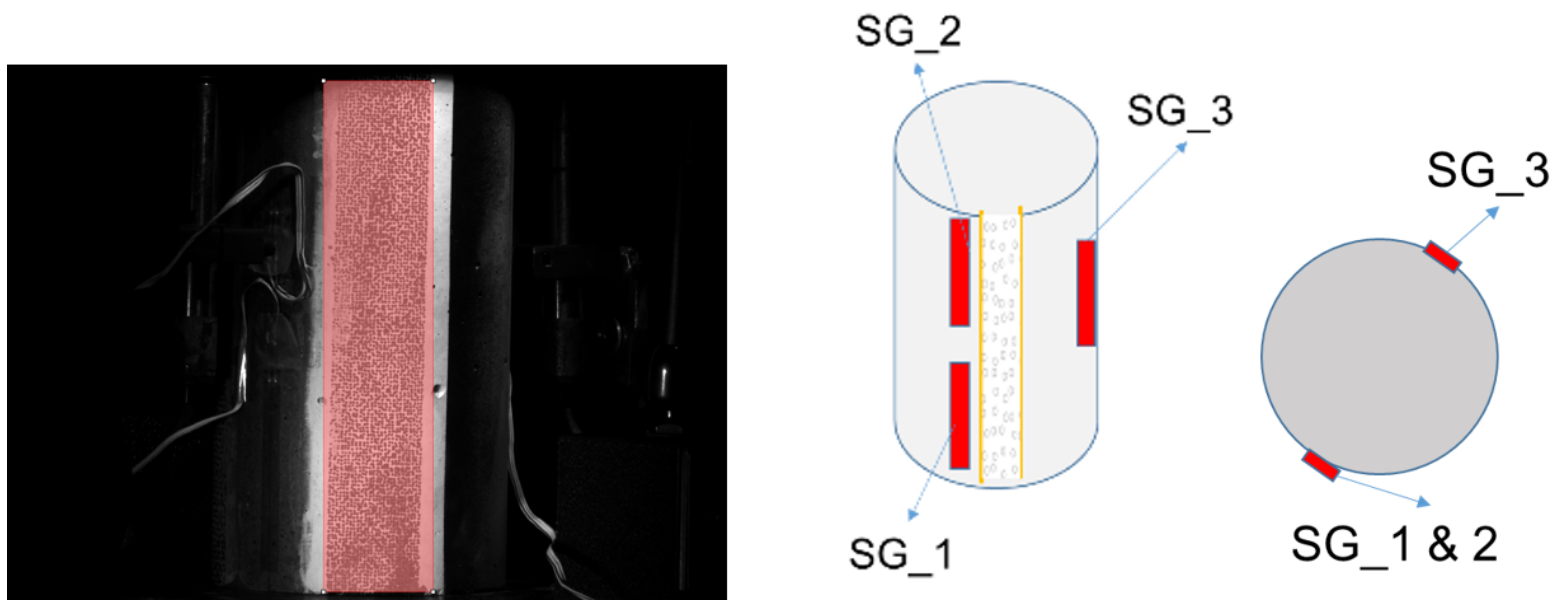

Figure 4.2. Concrete cylinder with applied speckle patterns and three attached strain gauges.

Figure 4.3a demonstrates a very good agreement between the total displacements of the test specimen captured by the DIC system and by the actuator. DIC-based strains over the gauge lengths in the vicinity of the strain gauges (SG1, SG2 and SG3) were also extracted from DICcollected data and plotted against the corresponding strain gauges in Figure 4.3(b, c, d): A good agreement between strains as captured by DIC and by strain gauges can also be observed.

The strong agreement among deformations captured by the DIC system, the actuator and the strain gauges at ambient temperature gives confidence to the reliability of all these measuring methods. As the actuator and Instron loading frame were insulated to ensure their minimal temperature increase during tests, the deformations captured by the actuator during 
thermal loading of test specimens were deemed reliable and thus used to assess the reliability of deformation captured by DIC technique at elevated temperatures, as presented in Section 4.2 .
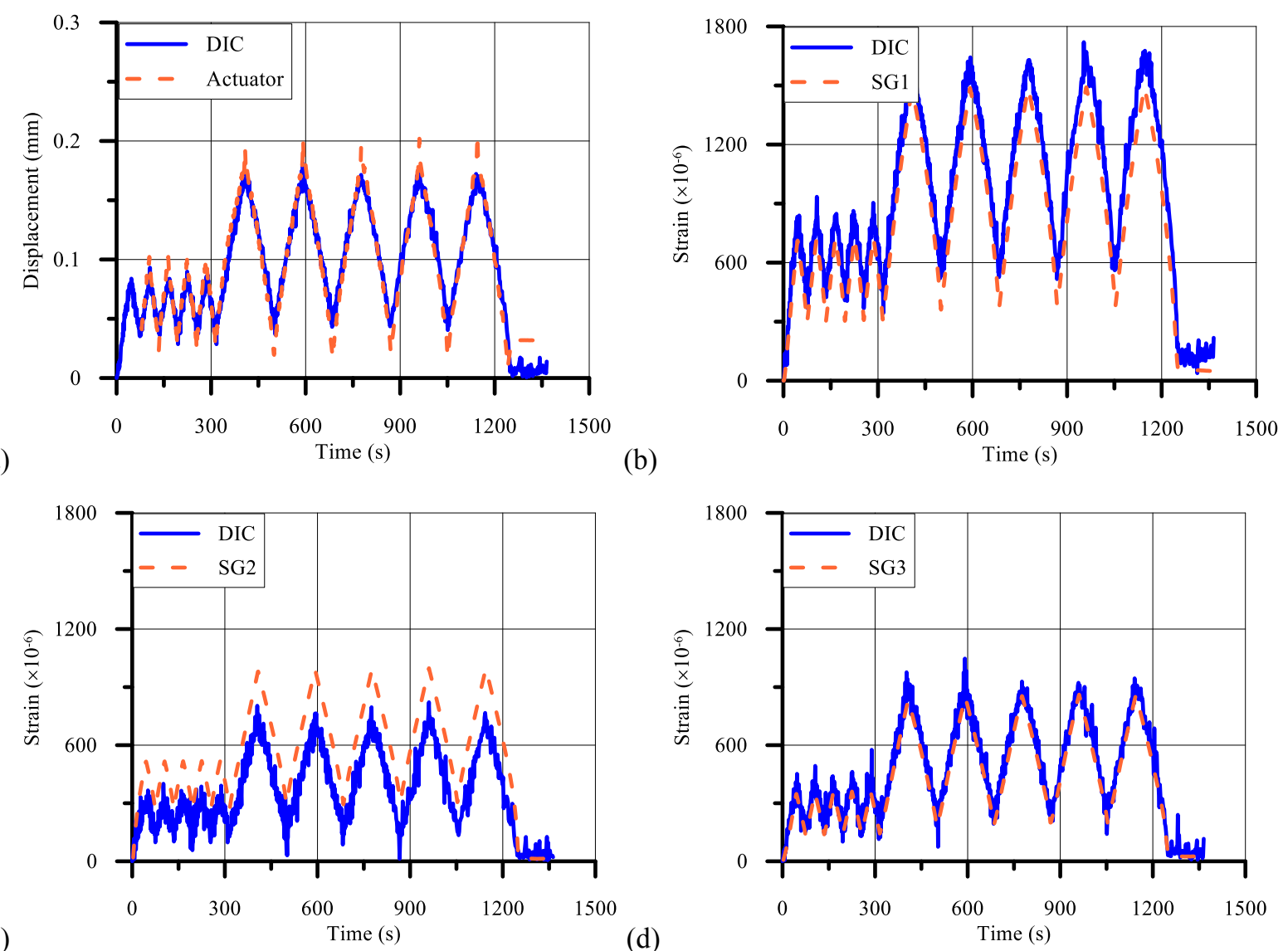

(c)

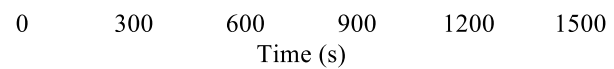

(d)

Figure 4.3. Comparisons between deformations captured by DIC and by actuator (a) and three strain gauges (b, c, d).

4.2. Establishing the reliability of deformation captured by the new DIC system at elevated temperatures using compression test

a) Heated specimens when radiant panels were turned off

In this series, three cylinders of $\phi 100 \mathrm{~mm}$ in diameter and $200 \mathrm{~mm}$ in height (namely S1, S2 and S3) were first heated by radiant panels until the target temperature of $150^{\circ} \mathrm{C}$ was reached at specimen depth of $21 \mathrm{~mm}$. Then, the radiant panels were turned off and the test specimens were compressed to failure under a constant displacement rate of $1 \mathrm{~mm}$ per minute. The resultant force-displacement curves captured by the DIC technique and by the actuator are plotted in Figure 4.4Error! Reference source not found.. It is clearly evidenced that there is a good agreement between displacements given by DIC system and those by the actuator. 

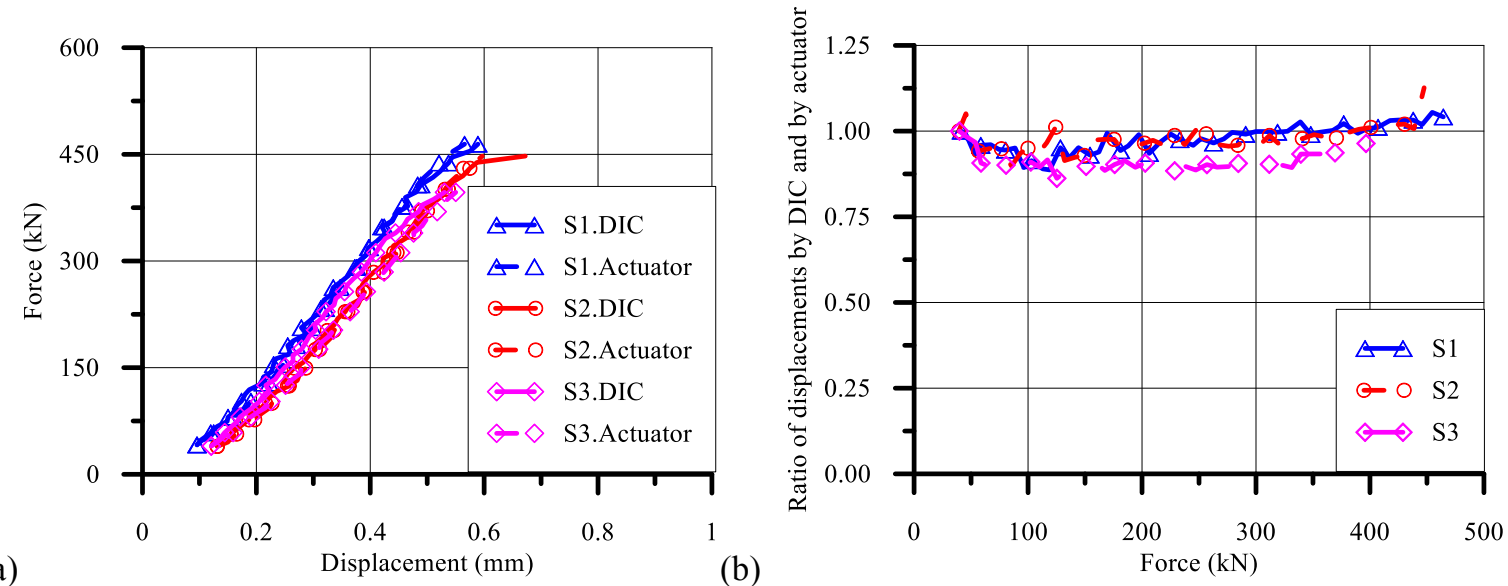

(a)

Figure 4.4. Displacement captured by DIC and actuator for three cylinders (a) and their ratios (b).

\section{b) Heated specimens when radiant panels were turned on}

In this test, the specimen was compressed under a constant load of $148 \mathrm{kN}$ (which was approximately $20 \%$ of the specimen's ultimate strength at ambient temperature) while being heated by radiant panels during the initial period, followed by a period in which the radiant panels were turned off (highlighted as "heating" and "cooling" in Figure 4.5). The variation over time of the total displacement of test specimen as captured by the DIC and the actuator is plotted in Figure 4.5, from which the following observations can be made:

- There appears a strong agreement between displacements given by DIC system and those by the actuator, giving further evidence of the reliability of this DIC system in capturing deformation of concrete structures at elevated temperatures.

- It is noticed that there was much more noise in displacements recorded by the DIC during heating when the radiant panels were on, compared to those during cooling when the radiant panels were off. This is possibly due to the interference of an air layer around the radiant panels when they were on - Such interference disappeared when the radiant panels were turned off. The effect of any change in light sources is deemed negligible, as demonstrated in Section 3.3. It is thus recommended that the cameras should be positioned in such a way to ensure their fields of view are not affected by the air layer around the radiant panels. 


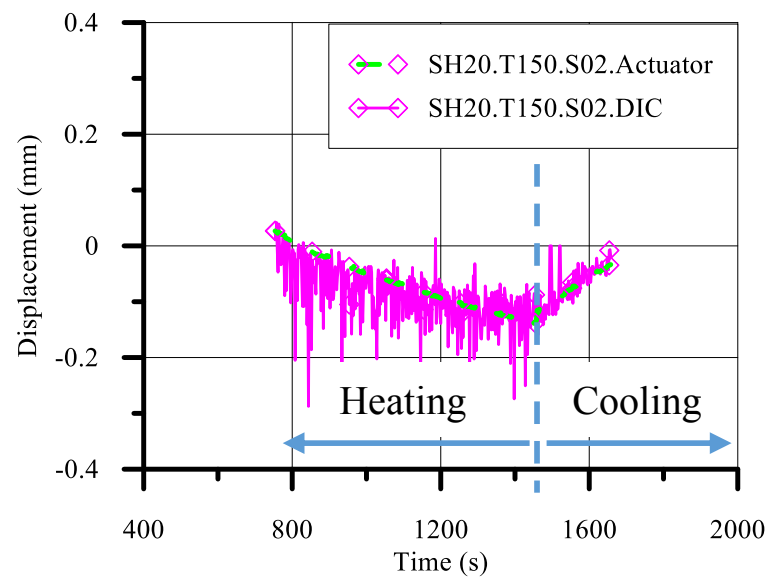

Figure 4.5. Displacement captured by DIC and actuator for cylinder specimens

\subsection{Establishing the reliability of deformation captured by DIC at elevated temperatures using rigid motion test}

The reliability of deformations captured by DIC at elevated temperatures was further confirmed using rigid motion test. The test specimen was displaced by known distances along the camera axes while being heated. It can be seen from Figure 4.6 and Table 2 that the movements as captured by DIC technique agree quite well with the corresponding applied rigid displacements, thereby giving further confidence on the reliability of the adopted DIC technique in capturing deformation at elevated temperatures.

(a)

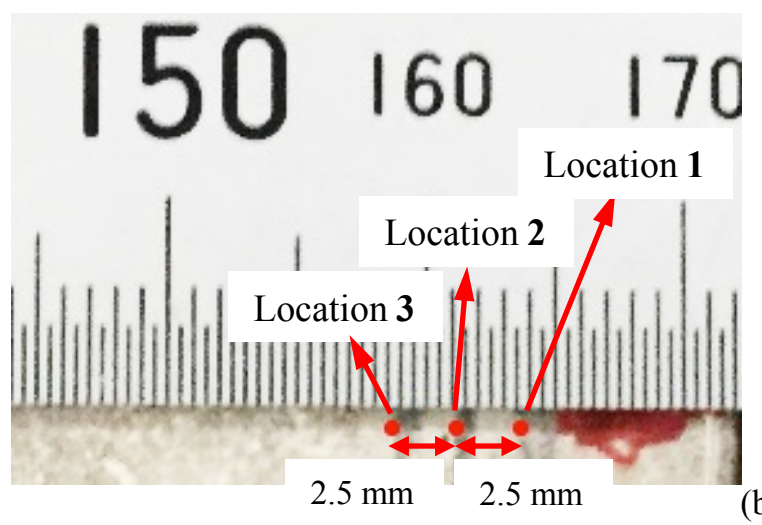

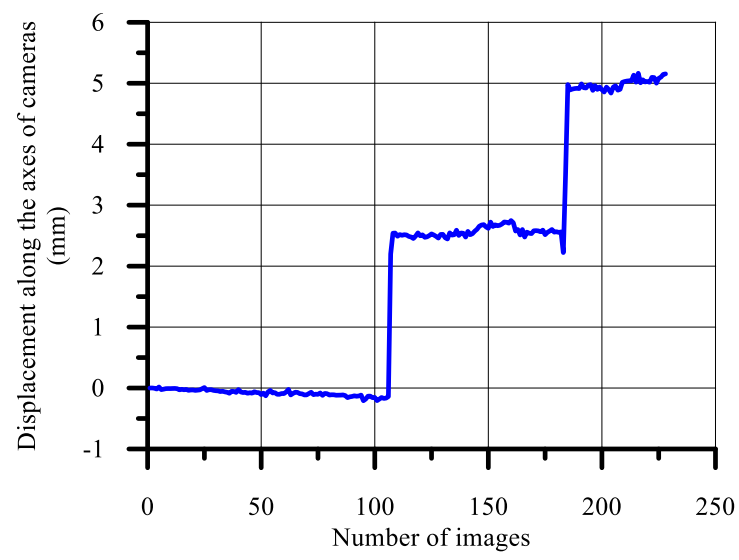

(b)

Figure 4.6. Measurement of rigid motions taken by (a) ruler and (b) DIC technique.

Table 2. Good agreement between movements as measured by ruler and DIC technique.

\begin{tabular}{ccc}
\hline Location & Movement as measured by ruler $(\mathrm{mm})$ & Movement as measured by DIC technique $(\mathrm{mm})$ \\
\hline 1 & 0.0 & -0.08 \\
2 & 2.5 & 2.55 \\
3 & 5.0 & 4.95
\end{tabular}

It is strongly evident from the above discussion that the newly-developed DIC system is capable of reliably capturing concrete deformation at both ambient and elevated temperatures. Ongoing work is being conducted to further enhance the reliability and workability range of the 
current DIC system. Further work is also ongoing to integrate such DIC system into the overall fire testing setup to allow to generate a comprehensive set of more reliable and realistic set of data. Likely applications of such setup and their potential positive impacts on the ongoing transitioning towards performance-based structural engineering design are discussed below:

- The accuracy on predicting fire performance of concrete structures of any models rely significantly on the quality of input parameter, inclusively mechanical properties such as Young's modulus, stress-strain relationships at elevated temperatures and loadinduced thermal strains essentially for members subjected to axial loads. These properties cannot be obtained properly without a reliable method for deformation capturing at high temperatures. Thus, development of such a measuring method as demonstrated in this paper is absolutely paramount.

- The application of DIC technique, once established, will enable the collection of fullfield transient displacement on the surfaces of heated regions throughout the heating and loading process. This will generate valuable sets of data on localised deformations and the associated temperatures that can be utilised for direct comparisons, analyses and validation of numerical models. The reliability and applicability of these models, which have been validated against these wide range of data, are inevitably enhanced. The time history of deformed geometry can also be obtained and studied for any localised effects or possible failure mechanisms. These benefits undoubtedly advance the current understanding on behaviour of concrete structures at elevated temperatures.

- The reliability of DIC technique at elevated temperatures, will also create the opportunities to investigate deeply into the spalling phenomenon, which is currently unable to be quantified. The DIC method using high-speed cameras will allow possibility to capture the onset of spalling on the surface of the concrete, correlating this with strain and corresponding stress, velocity and mass for spalling energy. This would greatly help to examine the problem of thermal-induced spalling in concrete.

\section{Summary and conclusions}

In this paper, a review of major relevant existing methods for measuring deformation of concrete structures at high temperatures is first presented. Key merits, limitations and remaining challenges of each method are briefed, highlighting that existing testing facilities and measuring instruments generally do not allow reliable direct measurement of deformation and strain of high-temperature concrete. Accordingly, the deformation has typically been captured either indirectly or outside the heated zones, unavoidably introducing additional uncertainty and errors that are difficult to be adequately quantified. It is also shown that one of the most promising techniques for deformation measurement at elevated temperatures is that using DIC, a full-field and non-contact solution. 
Based on that review, details of a new setup using DIC technique for full-field non-contact deformation capturing of concrete surface at elevated temperatures are given, with a focus on key features that help effectively address major challenges discussed in the earlier section. Evidence that give confidence to the reliability of such system is then presented.

Together with reliable thermal boundary conditions on test specimens, reliable full-field deformation capturing would allow to generate required data on mechanical, thermal and deformational response of concrete at elevated temperatures, thereby facilitating the development of effective rational fire design and analysis of concrete structures.

\section{Acknowledgements}

The authors acknowledge the financial support of Australian Research Council's Discovery Projects funding scheme (DP150102354).

\section{References}

1. Torero, J.L., Assessing the performance of concrete structures in fires. Concrete In Australia - Special Issue on "Concrete Performance in Fire" 2014. 40(3): p. 44-49.

2. Maluk, C., Motivation, drivers and barriers for a knowledge-based test environment in structural fire safety engineering science. Fire Safety Journal, 2017. 91(Supplement C): p. 103-111.

3. McAllister, T., et al., Measurement of Temperature, Displacement, and Strain in Structural Components Subject to Fire Effects: Concepts and Candidate Approaches. 2012, National Institute of Standards and Technology.

4. Gillie, M. and T. Stratford, Chapter 8: Behaviour of the Structure during the Fire, in The Dalmarnock Fire Tests: Experiments and Modelling, G. Rein, C.A. Empis, and R. Carve, Editors. 2007, The School of Engineering and Electronics, University of Edinburgh.

5. Castillo, C., Effect of transient high temperature on high-strength concrete. 1987, Rice University.

6. Sullivan, P.J.E., G.A. Khoury, and B.N. Grainger, Apparatus for measuring the transient thermal strain behaviour of unsealed concrete under constant load for temperatures up to $700^{\circ} \mathrm{C}$. Magazine of Concrete Research, 1983. 35(125): p. 229-236.

7. Ali, F., et al., Outcomes of a major research on fire resistance of concrete columns. Fire Safety Journal, 2004. 39(6): p. 433-445.

8. Benmarce, A. and M. Guenfoud, Experimental behaviour of high-strength concrete columns in fire. Magazine of Concrete Research, 2005. 57(5): p. 283-287.

9. Ali, F., A. Nadjai, and S. Choi, Numerical and experimental investigation of the behavior of high strength concrete columns in fire. Engineering Structures, 2010. 32(5): p. 1236-1243.

10. Martins, A.M.B. and J.P.C. Rodrigues, Fire resistance of reinforced concrete columns with elastically restrained thermal elongation. Engineering Structures, 2010. 32(10): p. 3330-3337.

11. Tan, K.-H. and T.-T. Nguyen, Structural responses of reinforced concrete columns subjected to uniaxial bending and restraint at elevated temperatures. Fire Safety Journal, 2013. 60: p. 1-13.

12. Seręga, S., Effect of transverse reinforcement spacing on fire resistance of high strength concrete columns. Fire Safety Journal, 2015. 71: p. 150-161. 
13. Khaliq, W., V. Kodur, and N. Raut, Comparative fire performance of high strength concrete columns with different types of fiber reinforcement. Applications of Structural Fire Engineering, 2015.

14. Tan, K.-H. and T.-T. Nguyen, Experimental behaviour of restrained reinforced concrete columns subjected to equal biaxial bending at elevated temperatures. Engineering Structures, 2013. 56: p. 823-836.

15. Hager, I. and P. Pimienta. Mechanical properties of HPC at high temperatures. in Proc. Int. Workshop fib Task Group, Fire Design of Concrete Structures: What now? What next. 2004.

16. Phan, L.T. and N.J. Carino, Effects of test conditions and mixture proportions on behavior of high-strength concrete exposed to high temperatures. ACI Materials Journal, 2002. 99(1).

17. Xiong, M.X. and J.Y.R. Liew, Mechanical behaviour of ultra-high strength concrete at elevated temperatures and fire resistance of ultra-high strength concrete filled steel tubes. Materials \& Design, 2016. 104: p. 414-427.

18. Long, T.P. and J.C. Nicholas, Effects of Test Conditions and Mixture Proportions on Behavior of High-Strength Concrete Exposed to High Temperatures. Materials Journal, 2002. 99(1).

19. Raut, N.K. and V.K.R. Kodur, Response of High-Strength Concrete Columns under Design Fire Exposure. Journal of Structural Engineering, 2011. 137(1): p. 69-79.

20. Dwaikat, M.M.S., et al., Experimental behavior of steel beam-columns subjected to fire-induced thermal gradients. Journal of Constructional Steel Research, 2011. 67(1): p. 30-38.

21. Adelzadeh, M., et al., Fibre optic sensors for high temperatures and fire scenarios, in First Middle East Conference on Smart Monitoring, Assessment and Rehabilitation of Civil Structures (SMAR 2011). 2011: Dubai, UAE.

22. Kodur, V.K.R., et al., Guidelines for Improving the Standard Fire Resistance Test Specifications. Journal of ASTM International, 2009. 6(7): p. 102275.

23. Y, H., et al., A Temperature Self-Compensated LPFG Sensor for Large Strain Measurements at High Temperature. IEEE Transactions on Instrumentation and Measurement, 2010. 59(11): p. 2997-3004.

24. Micro-Epsilon, Instruction Manual - optoNCDT 1302, Micro-Epsilon, Editor. 2008: 94496 Ortenburg Germany.

25. Sutton, M.A., J.J. Orteu, and H. Schreier, Image correlation for shape, motion and deformation measurements: basic concepts, theory and applications. 2009: Springer Science \& Business Media.

26. Al-Kamaki, Y.S.S., R. Al-Mahaidi, and I. Bennetts, An experimental investigation of the behaviour of heat-damaged RC columns confined with CFRP fabrics using photogrammetry. Materials and Structures, 2016. 50(1): p. 1-19.

27. Mahal, M., et al., Using digital image correlation to evaluate fatigue behavior of strengthened reinforced concrete beams. Engineering Structures, 2015. 105(Supplement C): p. 277-288.

28. De Wilder, K., et al., Experimental investigation on the shear capacity of prestressed concrete beams using digital image correlation. Engineering Structures, 2015. 82(Supplement C): p. 82-92.

29. Gencturk, B., et al., Use of digital image correlation technique in full-scale testing of prestressed concrete structures. Measurement, 2014. 47(Supplement C): p. 505-515.

30. Fayyad, T.M. and J.M. Lees, Experimental investigation of crack propagation and crack branching in lightly reinforced concrete beams using digital image correlation. Engineering Fracture Mechanics, 2017. 182(Supplement C): p. 487-505.

31. Lyons, J., J. Liu, and M. Sutton, High-temperature deformation measurements using digital-image correlation. Experimental mechanics, 1996. 36(1): p. 64-70. 
32. Leplay, P., et al., Identification of asymmetric constitutive laws at high temperature based on Digital Image Correlation. Journal of the European Ceramic Society, 2012. 32(15): p. 3949-3958.

33. Xiong, M.-X. and J.R. Liew, Mechanical behaviour of ultra-high strength concrete at elevated temperatures and fire resistance of ultra-high strength concrete filled steel tubes. Materials \& Design, 2016. 104: p. 414-427.

34. Bing, P., et al., High-temperature digital image correlation method for full-field deformation measurement at $1200{ }^{\circ} \mathrm{C}$. Measurement Science and Technology, 2011. 22(1): p. 015701.

35. Grant, B.M.B., et al., High-temperature strain field measurement using digital image correlation. The Journal of Strain Analysis for Engineering Design, 2009. 44(4): p. $263-$ 271.

36. Guo, X., et al., High-temperature digital image correlation method for full-field deformation measurement captured with filters at $2600^{\circ} \mathrm{C}$ using spraying to form speckle patterns. Optical Engineering, 2014. 53(6): p. 063101-063101.

37. Wei, W., et al., Measurement of high temperature full-field strain up to $2000{ }^{\circ} \mathrm{C}$ using digital image correlation. Measurement Science and Technology, 2017. 28(3): p. 035007.

38. Le, Q.X., et al., Effects of temperature and temperature gradient on concrete performance at elevated temperatures. Advances in Structural Engineering, 2017. 0(0): p. 1369433217746347.

39. Maluk, C., et al., A Heat-Transfer Rate Inducing System (H-TRIS) Test Method. Fire Safety Journal, 2016.

40. Song, Z., et al., Optical properties across the solar spectrum and indoor thermal performance of cool white coatings for building energy efficiency. Energy and Buildings, 2013. 63: p. 49-58.

41. Filtz, J.-R., et al., Improving heat fluxmeter calibration for fire testing laboratories (HFCAL), in NordTest Technical Reports. 2002.

42. $\quad$ EFFILUX, Structured LED Lighting, in EFFI-Lase-Datasheet. 2017.

43. Correlated Solutions, Vic-3D Manual. Correlated Solutions. Inc., Columbia, SC, 2010. 